\title{
N-Alkylation vs O-Alkylation: Influence on the Performance of a Polymeric Field-Effect Transistors Based on a Tetracyclic Lactam Building Block
}

\author{
Mian Cai, ${ }^{\dagger, \ddagger}, \|$ Zhiyuan Zhao, ${ }^{\S}, \|$ Yanfang Liu, ${ }^{\dagger}$ Xiao Wang, ${ }^{*}{ }^{\dagger}$ Yunqi Liu, ${ }^{\S}$ Zhenggang Lan, $^{\dagger}$ \\ and Xiaobo Wan ${ }^{*, \dagger, \ddagger(0)}$
}

${ }^{\dagger}$ CAS Key Laboratory of Bio-based Materials, Qingdao Institute of Bioenergy \& Bioprocess Technology, Chinese Academy of Sciences, 189 Songling Road, Qingdao 266101, People's Republic of China

${ }^{\S}$ Institute of Chemistry, Chinese Academy of Sciences, Beijing 100080, People's Republic of China

ॠUniversity of Chinese Academy of Sciences, Beijing 100049, People’s Republic of China

\section{Supporting Information}

ABSTRACT: Lactam-containing conjugated molecules are important building blocks for conjugated polymers for high performance organic field-effect transistors (OFETs). The alkylation on conjugated lactam building blocks may preferably produce either O-alkylated or $\mathrm{N}$-alkylated isomers, which might have different influences on the HOMO/LUMO energy levels, $\pi-\pi$ stacking patterns and crystallinity of the corresponding polymers. However, the influence of $\mathrm{O}$ alkylation and $\mathrm{N}$-alkylation on the OFET performance of the resultant polymers has not been reported. Here, with an improved synthetic strategy, we prepared the $\mathrm{N}$-alkylated isomer of dibenzonaphthyridinedione (DBND), a tetracyclic lactam building block that used to give O-alkylated product preferably, which gave us a chance to compare the influence of N-alkylated DBND ( $N$-DBND) and O-alkylated DBND (O-DBND) on the OFET performance of the corresponding polymers. It was found that the polymer based on N-DBND exhibits a much higher hole mobility $\left(0.55 \mathrm{~cm}^{2} \mathrm{~V}^{-1} \mathrm{~s}^{-1}\right)$, almost 100 times greater than the one based on $O$-DBND $\left(0.006 \mathrm{~cm}^{2} \mathrm{~V}^{-1} \mathrm{~s}^{-1}\right)$. The reasons for such a huge difference were thoroughly investigated theoretically and experimentally. It was found that repeating unit in the polymer based on $N$-DBND exhibits a much higher dipole moment $(1.56 \mathrm{D})$ than that based on O-DBND $(0.49 \mathrm{D})$, which results in a much stronger intermolecular binding energy $\left(-57.2 \mathrm{vs}-30.0 \mathrm{kcal} \mathrm{mol}^{-1}\right)$. Although both polymers exhibits very similar coplanarity and crystalline patterns, stronger intermolecular interaction of the polymer based on $N$-DBND leads to shorter $\pi-\pi$ stacking distance ( 3.63 vs $3.68 \AA$ ), which results in a film with higher crystallinity and highly interconnected fibrillar domains, and accounts for its high charge carrier mobility, as evidenced by 2D-GIXD and AFM analysis. We come to the conclusion that the more polar amide bond in N-DBND is the major factor which governs the charge transport properties, which overwhelms the side-chain engineering effect that $\mathrm{O}$-alkylation might bring in (the branching point of the side-chain of an O-DBND-based polymer is one more atom away from the polymer backbone and results in less steric hindrance).

\section{INTRODUCTION}

In the past few years, donor-acceptor (D-A) type conjugated polymers with amide/lactam building blocks have attracted great attention. Amide-based organic semiconducting materials are widely investigated for applications in organic field-effect transistors (OFETs) and organic photovoltaics (OPVs) due to their low-lying HOMO levels and the improved $\pi-\pi$ stacking endowed by the polar and electron-deficient amide bond. ${ }^{1,2}$ For example, polymers based on diketopyrrolopyrrole (DPP) and isoindigo (II), two most popular lactam-containing acceptor building blocks, exhibited superior performance both in OFETs and OPVs. ${ }^{3-7}$ Extensive efforts were put into the discovery of novel lactam-containing materials ${ }^{8-12}$ thereafter, and further optimizations such as the extension of conjugation length, ${ }^{13-15}$ side-chain engineering, ${ }^{16-18}$ and heteroatom incorporation $^{19-22}$ on these structures were widely investigated, which not only led to the enhanced performance, but also disclosed the relationship between chemical structures and material properties, which boosted the rapid development of organic semiconductors in recent years.

One of the advantages in using amide/lactam-containing conjugated building blocks is the ease to alkylate the amide/ lactam moiety to endow the corresponding polymers with solution processability. On the other hand, amide/lactam moiety provides two possible positions for alkylation: either on the $\mathrm{N}$ atom or on the $\mathrm{O}$ atom. Although $\mathrm{N}$-alkylated lactamcontaining conjugated motifs continue attracting considerable attention, O-alkylated lactam isomers also present in the

Received: July 24, 2017

Revised: October 17, 2017

Published: October 27, 2017 
Scheme 1. (a) Optimization of the Synthetic Conditions for Monomer N-DBND and (b) Polymer Synthesis and Polymerization Conditions $^{a}$

(a) Optimization of the synthesis of $N$-DBND over O-DBND

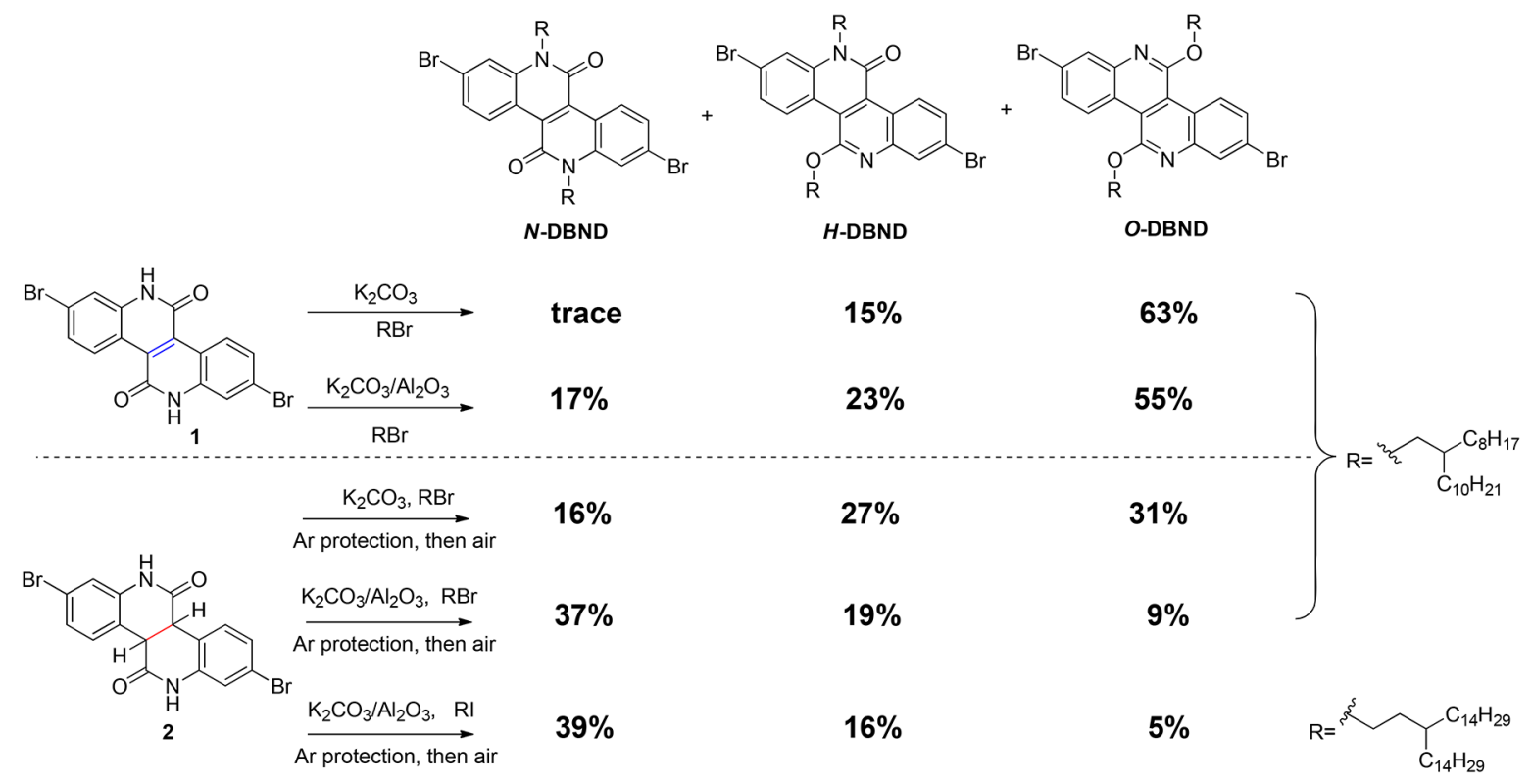

(b) Polymer synthesis
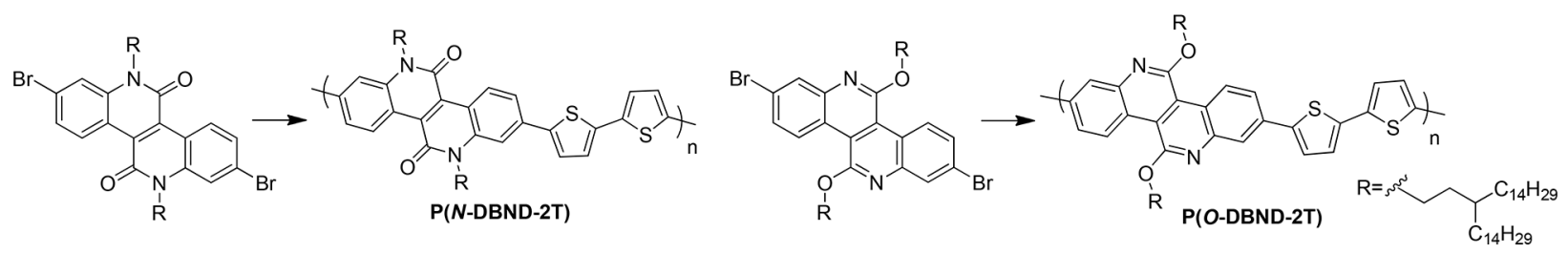

${ }^{a} \mathrm{Pd}_{2}(\mathrm{dba})_{3}, \mathrm{P}(o \text {-tol })_{3}, 5,5^{\prime}$-bis (trimethylstannyl)-2,2'-bithiophene, toluene, $110{ }^{\circ} \mathrm{C}, 72 \mathrm{~h}$.

literature with satisfying performance both in OFETs and OPVs. ${ }^{10,23}$ In some cases, alkylation of the lactam moiety in a $\pi$-conjugated system only led to O-alkylation. For example, a thiophene-fused naphthyridinedione based polymer showed high efficiency in polymeric wide-bandgap OPVs, ${ }^{10}$ and it was later confirmed that the alkylation occurs solely on oxygen atom instead of on nitrogen atom. In such cases, the driving force for the formation of O-alkylated compounds is aromatization, ${ }^{24}$ which leads to a fully conjugated system with better stability. From a synthetic chemistry point of view, certain alkylation conditions generally leads to one of the two isomers, thus, it is difficult to obtain both O-alkylated and $\mathrm{N}$ alkylated isomers and compare their influence on the performance of corresponding polymers. Only a few works are reported on that topic, majorly focused on their influence on OPV performance. ${ }^{25,26}$ Leclerc et al. reported that by incorporating both $\mathrm{N}$-alkylated and O-alkylated phenanthridionone into the conjugated polymer, the OPV performance of the polymer is better than that made from either $\mathrm{N}$-alkylated or Oalkylated monomer. ${ }^{24} \mathrm{Su}$ et al. compared the OPV performance of the polymers containing either $\mathrm{N}$-alkylated and O-alkylated pyrido $[2,3,4,5-\mathrm{lmn}]$ phenanthridine, and came to the conclusion that $\mathrm{N}$-alkylated polymer shows a slightly better power conversion efficiency. ${ }^{25}$ However, the reason behind such differences is not thoroughly discussed. Furthermore, to the best of our knowledge, the influence of $\mathrm{N}$-alkylated and $\mathrm{O}$ alkylated monomers on the performance of the corresponding polymer in OFET devices has not been reported so far. We consider that $\mathrm{N}$-alkylation and O-alkylation on the lactam moiety of a conjugated monomer may have two consequences of the corresponding polymers: (1) N-alkylation results in a monomer with an intact lactam moiety, which is more polar than O-alkylated isomer and may favor stronger intermolecular interactions and thus may be beneficial to interchain charge transfer; (2) on the other hand, O-alkylation results a monomer with the branching point of the side-chain one more atom away from the polymeric backbone, which may decrease the steric hindrance caused by side-chain and thus may also be beneficial to OFET performance, as evidenced by many side-chain engineering works on conjugated polymers. ${ }^{17,27}$ We anticipate that if one factor overwhelms the other, it will become the determining effect for the corresponding OFET performance. Such studies will further cast light on the "structure-property" relationship of the conjugated polymers.

Recently we reported the synthesis of a tetracyclic fused bisamides building block, dibenzo $[c, h][2,6]$-naphthyridine$5,11(6 H, 12 H)$-dione (DBND) and tested the OPVs performance of the corresponding O-alkylated polymer. ${ }^{28}$ During the alkylation reaction on DBND, O-alkylated DBND (noted as $O$ DBND) was the major product, with a small amount of half $\mathrm{O}$ alkylated/half N-alkylated DBND (noted as H-DBND), and barely no formation of $\mathrm{N}$-alkylated DBND (noted as $\mathrm{N}$ DBND). Herein, we report our improvement in the synthesis of $\mathrm{N}$-DBND, which allows us to compare $\mathrm{N}$-alkylation and $\mathrm{O}$ - 
Table 1. Molecular Weights, Optical Properties, and Electrical Properties

$\begin{array}{cccccccc}\text { polymer } & M_{\mathrm{n}}{ }^{a}(\mathrm{kDa}) & \mathrm{PDI}^{a} & \lambda_{\max }{ }^{b}(\mathrm{~nm}) & \lambda_{\text {edge }}^{b}(\mathrm{~nm}) & E_{\mathrm{g}}{ }^{\mathrm{ppt}}(\mathrm{eV}) & E_{\text {ox }}(\mathrm{V}) & \mathrm{IP}^{c}(\mathrm{eV}) \\ \mathrm{P}(\text { N-DBND-2T }) & 55 & 2.56 & 551,509 & 575 & 2.16 & 1.40 & 5.55 \\ \mathrm{P}(\text { O-DBND-2T }) & 81 & 2.21 & 505,472 & 541 & 2.29 & 1.29 & 5.44\end{array}$

${ }^{a}$ Determined by GPC at $150{ }^{\circ} \mathrm{C}$ using TCB as the eluent. ${ }^{b}$ Films are prepared by spin-coated the polymer solution on the piezoid. ${ }^{c}$ Films are prepared by dropping-casted the polymer solution on the working electrode.
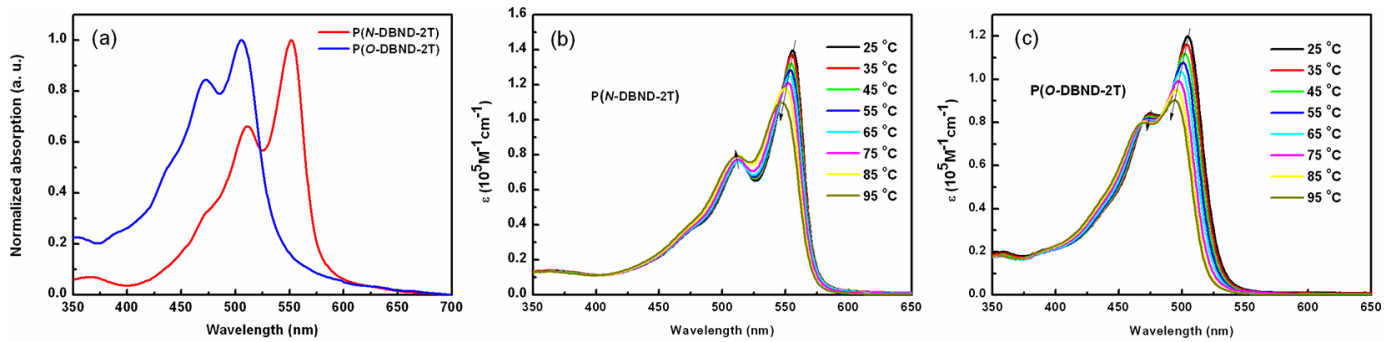

Figure 1. (a) UV-vis absorption spectra of polymer films. (b, c) Temperature-dependent UV-vis absorption spectra of $\mathrm{P}(N-\mathrm{DBND}-2 \mathrm{~T})$ and $\mathrm{P}(\mathrm{O}$ DBND-2T) in diluted $o$-DCB $\left(0.01 \mathrm{~g} \mathrm{~L}^{-1}\right)$.

alkylation of the lactam ring on the OFET performance of the resulting polymers. The results indicate that although with the side-chain branching point one atom closer to the main chain, polymer based on N-DBND shows almost one hundred times higher hole mobility $\left(0.55 \mathrm{~cm}^{2} \mathrm{~V}^{-1} \mathrm{~s}^{-1}\right)$ than that based on $O$ DBND $\left(0.006 \mathrm{~cm}^{2} \mathrm{~V}^{-1} \mathrm{~s}^{-1}\right)$, since the more polar amide bond leads to stronger interchain $\pi-\pi$ stacking, which is the overwhelming effect which governs the charge transportation.

\section{RESULTS AND DISCUSSION}

Synthesis of N-Alkylated and O-Alkylated DBND. DBND, a novel isomer of II, is a fully planar molecule (II exhibits a $22.3^{\circ}$ dihedral angle between the two oxindole rings ${ }^{29}$ ), and the O-alkylated DBND has been used as an excellent building block for wide-bandgap conjugated polymers with outstanding OPV performance. ${ }^{28}$ We expected that the planarity and strong $\pi-\pi$ interaction of DBND due to the presence of lactam ring might facilitate intermolecular $\pi-\pi$ stacking of the corresponding polymers, thus might also lead to excellent OFETs performance. Also, if the N-alkylated DBND could be prepared, the study on the influence of O-alkylation and N-alkylation of DBND on the OFET performance of the corresponding polymers would be very interesting.

However, the limitation at that time was that during the alkylation reaction of DBND, $O$-DBND was the obtained as the major product; $H$-DBND was also observed but the yield of $N$ DBND was rather limited. The overwhelming preference of $\mathrm{O}$ alkylation over $\mathrm{N}$-alkylation is due to the aromatic character of $O$-DBND. ${ }^{24}$ It was also confirmed by NMR data of the unsubstituted DBND: it exists as a mixture of bis-lactam form and lactam/quinolinol form in a 48:52 ratio due to tautomerization. ${ }^{28}$ Similar results were also observed in the alkylation of 2-pyridone, and the exclusive O-alkylation in conjugation enlarged systems reported by Andersson ${ }^{10}$ and Liu. $^{23^{\circ}}$

In order to improve the regioselectivity for $\mathrm{N}$-alkylation (branched C20 side-chain: 9-(bromomethyl)nonadecane was used for the optimization of alkylation reactions), two methods were adopted, as shown in Scheme 1. First, by loading $\mathrm{K}_{2} \mathrm{CO}_{3}$ onto a solid support such as $\mathrm{Al}_{2} \mathrm{O}_{3},{ }^{30}$ the yield of $\mathrm{N}$-DBND increased to $17 \%$, while the production of $O$-DBND decreased from $63 \%$ to $55 \%$ when compared with the $\mathrm{K}_{2} \mathrm{CO}_{3}$-only conditions. The improvement may be due to the coordination of the carbonyl oxygen atom with the polyhydric $\mathrm{Al}_{2} \mathrm{O}_{3}$ surface, which decreases the chances for O-alkylation. However, such an increase was still not satisfying for the preparation of $\mathrm{N}$ alkylated product in large quantity. Since the aromatization is the driven force of O-alkylation, we then decided to circumvent this problem by using the unconjugated precursor (compound 2) of DBND as the substrate for alkylation. Delightfully, the alkylation reaction on compound 2 first under argon protection and then exposed air directly afforded N-DBND with an improved yield of $16 \%$. By combining the two methods together, we could reverse the regioselectivity to $37 \%$ yield of $N$-DBND, $19 \%$ of $H$-DBND and $9 \%$ of O-DBND. We anticipate that such a synthetic strategy could also be applied to the selective $\mathrm{N}$-alkylation of other similar lactam-containing conjugated monomers which generally prefer O-alkylation under conventional conditions.

Polymer Synthesis and General Characterization. With C20 side-chain alkylated N-DBND and O-DBND in hand, Stille-coupling polymerization of the two building blocks with 5,5'-bis(trimethylstannyl)-2,2'-bithiophene (2T) was conducted, giving the corresponding polymers in high yields. However, unlike O-DBND based polymer, $N$-DBND based polymer shows a rather poor solubility in common solvents such as chloroform, chlorobenzene or $o$-dichlorobenzene (oDCB) even at high temperature up to $140{ }^{\circ} \mathrm{C}$, which might be due to its stronger intermolecular packing. Thus, we were unable to fully characterize the properties of $N$-DBND based polymer, not to mention the comparison of the influence of $\mathrm{O}$ alkylation and $\mathrm{N}$-alkylation on OFET performance. Therefore, alkylation reagent with longer C31 side-chain (15-(2iodoethyl)nonacosane) was adopted: the larger alkyl group would improve the solubility of N-DBND based polymer; and the branching point further away from the backbone would generate less steric hindrance between alkyl chain and central core and reduced $\pi-\pi$ distance. ${ }^{17}$ The one-bath alkylation reaction with $\mathrm{K}_{2} \mathrm{CO}_{3} / \mathrm{Al}_{2} \mathrm{O}_{3}$ as the base also preferably resulted in $39 \%$ yield of C31 alkylated N-DBND, as shown in Scheme 1, similar to the yield when using 9-(bromomethyl)nonadecane as the alkylation reagent.

The newly synthesized monomers were then polymerized with 2T, purified, and collected to give the final polymers noted as $\mathrm{P}(\mathrm{N}-\mathrm{DBND}-2 \mathrm{~T})$ and $\mathrm{P}(\mathrm{O}-\mathrm{DBND}-2 \mathrm{~T})$, respectively. The 

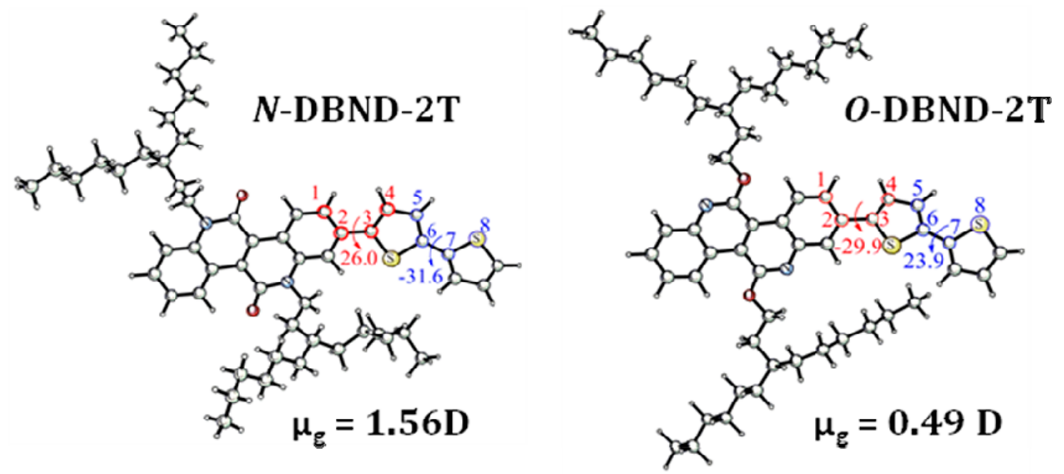

Figure 2. DFT calculation of the converged molecular structure of N-DBND-2T and O-DBND-2T. The intramolecular dihedral angle, ground state dipole moments are listed.

solubility of $\mathrm{P}(\mathrm{N}$-DBND-2T $)$ is improved to $20 \mathrm{mg} \mathrm{mL}^{-1}$ in $o$ $\mathrm{DCB}$ at $140^{\circ} \mathrm{C}$, but still not as good as $\mathrm{P}(\mathrm{O}$-DBND-2T) $(30$ $\left.\mathrm{mg} \mathrm{mL} \mathrm{m}^{-1}\right)$. The molecular weight were determined via gel permeation chromatography (GPC) using 1,2,4-trichlorobenzene as the eluent at $150{ }^{\circ} \mathrm{C}$ after calibration against polystyrene standards. The average molecular weights $\left(M_{n}\right)$ and polydispersity index (PDI) are shown Table 1. P $(N$ DBND-2T) exhibits a relatively lower $M_{\mathrm{n}}(55 \mathrm{kDa})$ compared to that of $\mathrm{P}(\mathrm{O}-\mathrm{DBND}-2 \mathrm{~T})(81 \mathrm{kDa})$, presumably due to its poorer solubility, which hinders further chain growth.

Optical and Electrochemical Properties. Figure 1a shows the UV-Vis absorption spectra of the two polymers in film state, and the related data are listed in Table 1 . Both polymers exhibit two similar and well-defined absorption peaks. The absorption peaks $\left(\lambda_{0-1}\right)$ at 472 and $510 \mathrm{~nm}$ stand for the ICT absorption, while the strong vibronic absorptions $\left(\lambda_{0-0}\right)$ at 505 and $551 \mathrm{~nm}$ arise from the aggregation of the polymer chains for $\mathrm{P}(\mathrm{O}-\mathrm{DBND}-2 \mathrm{~T})$ and $\mathrm{P}(\mathrm{N}-\mathrm{DBND}-2 \mathrm{~T})$, respectively. $\mathrm{P}(\mathrm{N}$-DBND-2T) shows a more red-shifted absorption, since the amide moiety exhibits stronger electron withdrawing ability than the O-alkylated pyridin-2-ol moiety.

In order to understand the different aggregation behavior of $\mathrm{N}$ - and $\mathrm{O}$-alkylated polymers, temperature-dependent $\mathrm{UV}$-vis absorption spectra in solution state were recorded to analyze the rigidity and intermolecular interaction of both polymers. The experiments were performed in a dilute $o$-DCB solution with temperature ranging from 25 to $95^{\circ} \mathrm{C}$. As shown in Figure 1 , parts $b$ and $c$, the vibronic absorptions of both polymers gradually decay with the increase of solution temperature, which is accompanied by a slight blue-shift, indicating the weaker intermolecular packing at higher temperature. However, the $\lambda_{0-0}$ vibronic absorption did not vanish even when the temperature was heated up to $95{ }^{\circ} \mathrm{C}$, indicating strong intermolecular stacking still exists at high temperature, which might be attributed to the highly planar DBND structure. However, the absorption decay rate of $\mathrm{P}(N-\mathrm{DBND}-2 \mathrm{~T})$ is much slower than that of $\mathrm{P}(\mathrm{O}-\mathrm{DBND}-2 \mathrm{~T})$, suggesting a stronger $\pi-\pi$ interaction between $\mathrm{N}$-alkylated polymeric chains. The intensity ratio of $I_{0-0} / I_{0-1}$ between $\lambda_{0-0}$ and $\lambda_{0-1}$ was calculated to further estimate the aggregation behavior in solution. ${ }^{31}$ For both polymers, the $I_{0-0} / I_{0-1}$ values decrease almost linearly with the increase of the temperature (measured at $10{ }^{\circ} \mathrm{C}$ interval, as shown in Figure S1). However, the $I_{0-0} /$ $I_{0-1}$ value of $\mathrm{P}(\mathrm{N}-\mathrm{DBND}-2 \mathrm{~T})$ is larger than that of $\mathrm{P}(\mathrm{O}-\mathrm{DBND}$ 2T), especially at low temperature, indicating that the aggregation of $\mathrm{P}(\mathrm{N}-\mathrm{DBND}-2 \mathrm{~T})$ is tighter. Such a result is also in accordance with the different solubilities of the two polymers, suggesting that $\mathrm{N}$-alkylation has a more positive influence in promoting $\pi-\pi$ stacking of the lactam-containing polymers.

The optical bandgaps of both polymers were calculated from the absorption edge of the films. The absorption edge is 575 $\mathrm{nm}$ for $\mathrm{P}(\mathrm{N}$-DBND-2T $)$ and $541 \mathrm{~nm}$ for $\mathrm{P}(O-\mathrm{DBND}-2 \mathrm{~T})$, which is corresponding to an optical bandgap $\left(E_{\mathrm{g}}{ }^{\text {opt }}\right)$ of 2.16 and $2.29 \mathrm{eV}$, respectively. The wider bandgap of $\mathrm{P}(O-\mathrm{DBND}$ 2T) indicates the weaker electron deficiency of O-alkylated DBND. Electrochemical cyclic voltammetry $(\mathrm{CV})$ was used to measure the ionization potential (IP) and the electron affinity (EA) of the polymers (Figure S2), which partially reflects the HOMO/LUMO energy level. ${ }^{32}$ The IP values of the polymers are determined from the onset of the oxidation peak, which are summarized in Table 1 . The onset of the oxidation potential of $\mathrm{P}(N$-DBND-2T) and $\mathrm{P}(O-\mathrm{DBND}-2 \mathrm{~T})$ is 1.40 and $1.29 \mathrm{~V}$ (vs $\mathrm{Ag} / \mathrm{AgCl}$ ), corresponding to a IP value of 5.55 and $5.44 \mathrm{eV}$, respectively. The high IP reflects a high lying HOMO energy level, suggesting that the transistor based on both polymers would exhibit hole-only charge transfer characteristics. Unfortunately, no well-defined reduction peak was observed, so we could not determine the exact EA of the polymers at this time.

Theoretical Calculation. To further discuss the difference of aggregation behavior between the two polymers, Density functional theory (DFT) calculation at $\omega \mathrm{B} 97 \mathrm{XD} / 6-31 \mathrm{G}^{*}$ level is used to study the energy-minimized structures as well as the intermolecular self-assembly binding energy (IBE). For the sake of computational simplicity, the 15-ethylnonacosane group (C31 chain) are replaced by 7-ethyltridecane (C15 chain). The result is shown in Figure 2. The dihedral angle between DBND and the thiophene ring are $26.0^{\circ}$ and $-29.9^{\circ}$ for N-DBND-2T and O-DBND-2T respectively, and that between the two thiophene rings are $-31.6^{\circ}$ and $+23.9^{\circ}$, respectively. Thus, the planarity of $N$-DBND-2T is comparable to O-DBND-2T. Nevertheless, the calculated IBE (Figure S3) of N-DBND-2T is $-57.2 \mathrm{kcal} \mathrm{mol}^{-1}$, which is $27.2 \mathrm{kcal} \mathrm{mol}^{-1}$ larger than that of $O$-DBND-2T, suggesting that $\mathrm{P}(\mathrm{N}$-DBND-2T $)$ have a stronger intermolecular interaction and greater tendency for stacking. ${ }^{33,34}$ Since $N$-DBND exhibits stronger electron deficiency, we propose that the different intermolecular interactions originate from the different intramolecular dipole moment. As is shown in Figure 2, N-DBND-2T shows a dipole moment of $1.56 \mathrm{D}$, while $O$-DBND-2T only exhibits a dipole moment of $0.49 \mathrm{D}$. The larger dipole moment could enhance the crystalline properties, which may also promote intermolecular charge transfer. 

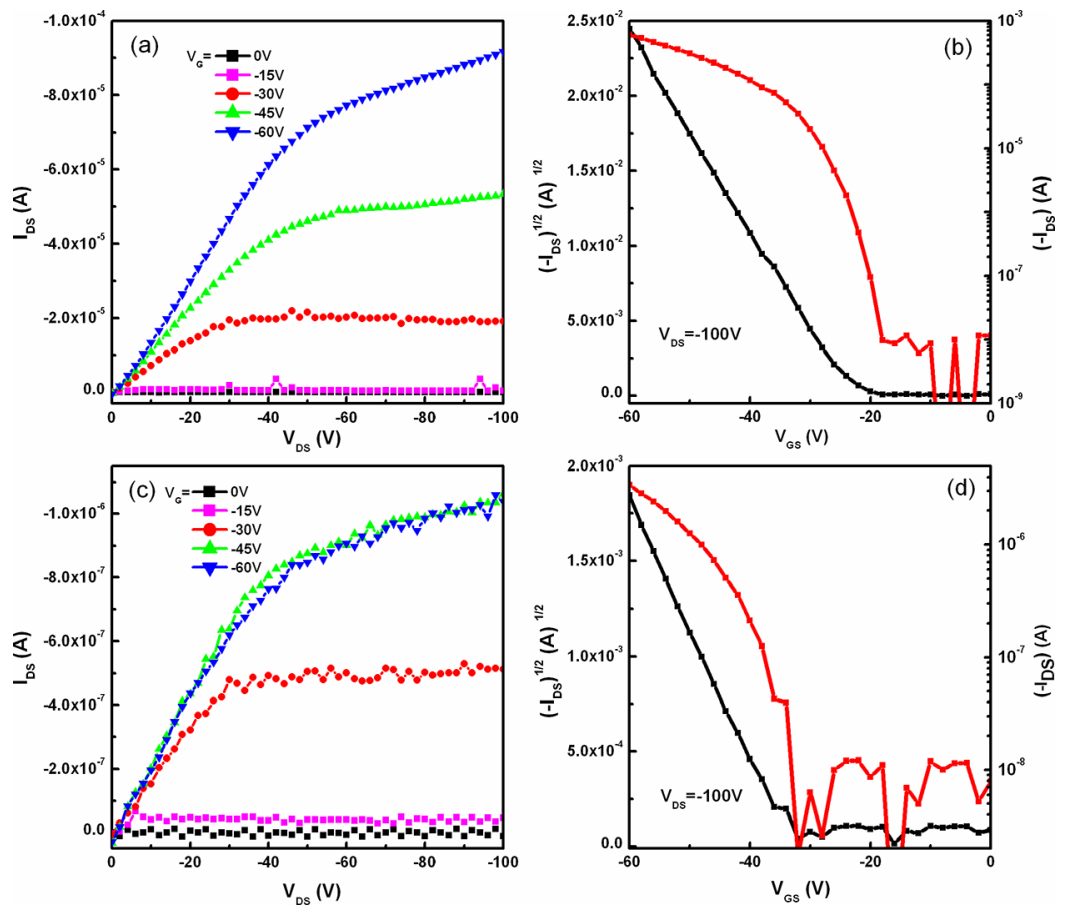

Figure 3. Output $(a$ and $c)$ and transfer $(b$ and $d)$ characteristics of $P(N-D B N D-2 T)$ and $P(O-D B N D-2 T)$ devices after thermal annealing $(L=10$ $\mu \mathrm{m}, W=1.4 \mathrm{~mm})$.

OFET Properties. To compare the OFET performance between $\mathrm{O}$-alkylated and $\mathrm{N}$-alkylated polymers, bottom-gate bottom-contact (BGBC) devices were constructed, the output and transfer curves are shown in Figure 3, and the optimized performances are listed in Table 2. As we expected, both

Table 2. OFET Device Performances and GIXD Results of Polymers

$\begin{array}{ccccc}\text { polymer } & \mu^{a}\left(\mathrm{~cm}^{2} \mathrm{~V}^{-1} \mathrm{~s}^{-1}\right) & \begin{array}{c}V_{\text {th }} \\ (\mathrm{V})\end{array} & I_{\text {on }} / \mathrm{I}_{\text {off }} & \begin{array}{c}\pi-\pi \text { distance }^{b} \\ (\AA)\end{array} \\ \mathrm{P}(N-\mathrm{DBND}-2 \mathrm{~T}) & 0.55 & -23 & >10^{4} & 3.63 \\ \mathrm{P}(\text { O-DBND-2T }) & 0.006 & -34 & >10^{2} & 3.68\end{array}$

${ }^{a}$ Maximum values of hole mobilities are measured under ambient condition after annealing at $180{ }^{\circ} \mathrm{C}$ for 6 min. ${ }^{b} \pi-\pi$ stacking distances determined by GIXD experiments.

polymers exhibit hole-only charge transfer characteristics due to the high lying HOMO energy level. $\mathrm{P}(O-\mathrm{DBND}-2 \mathrm{~T})$ exhibits an optimized hole mobility of $0.006 \mathrm{~cm}^{2} \mathrm{~V}^{-1} \mathrm{~s}^{-1}$. On the other hand, $\mathrm{P}(N-\mathrm{DBND}-2 \mathrm{~T})$ exhibits a much higher mobility up to $0.55 \mathrm{~cm}^{2} \mathrm{~V}^{-1} \mathrm{~s}^{-1}$, almost 100 times higher than that of $\mathrm{P}(\mathrm{O}$ -
DBND-2T). $\mathrm{P}(\mathrm{N}-\mathrm{DBND}-2 \mathrm{~T})$ also shows larger on/off ratio $\left(>10^{4}\right)$ than $\mathrm{P}(\mathrm{O}-\mathrm{DBND}-2 \mathrm{~T})\left(I_{\mathrm{on} / \mathrm{off}}>10^{2}\right)$, indicating that it is a better material for the fabrication of OFET devices. Although the molecular weight of $\mathrm{P}(\mathrm{N}-\mathrm{DBND}-2 \mathrm{~T})$ is lower than that of $\mathrm{P}(\mathrm{O}$-DBND-2T) (higher molecular weight generally results in higher charge carrier mobility for conducting polymers), and the side-chain branching point of $\mathrm{P}(\mathrm{N}$-DBND-2T $)$ is one atom closer from the backbone than that of $\mathrm{P}(\mathrm{O}-\mathrm{DBND}-2 \mathrm{~T})$, the much higher hole mobility of $\mathrm{P}(\mathrm{N}$-DBND-2T $)$ indicates that the higher electron deficiency character of $\mathrm{N}$-alkylated lactam acceptor is the overwhelming factor, which may be responsible to its higher charge transport properties.

GIXD and Morphology. To further explain the different performance in OFETs of the O-alkylated and $\mathrm{N}$-alkylated polymers, the crystallinity and morphology of the thin films were investigated by grazing incidence X-ray diffraction (GIXD) and tapping-mode atomic force microscopy (AFM). As shown in Figure 4a, both polymer films displays a strong diffraction at the $2 \theta$ value of $2.98^{\circ}$, corresponding to a $d$ spacing of $29.6 \AA(\lambda=1.54 \AA)$. The other three diffractions are attributed to the (200), (300), and (400) diffractions, indicating
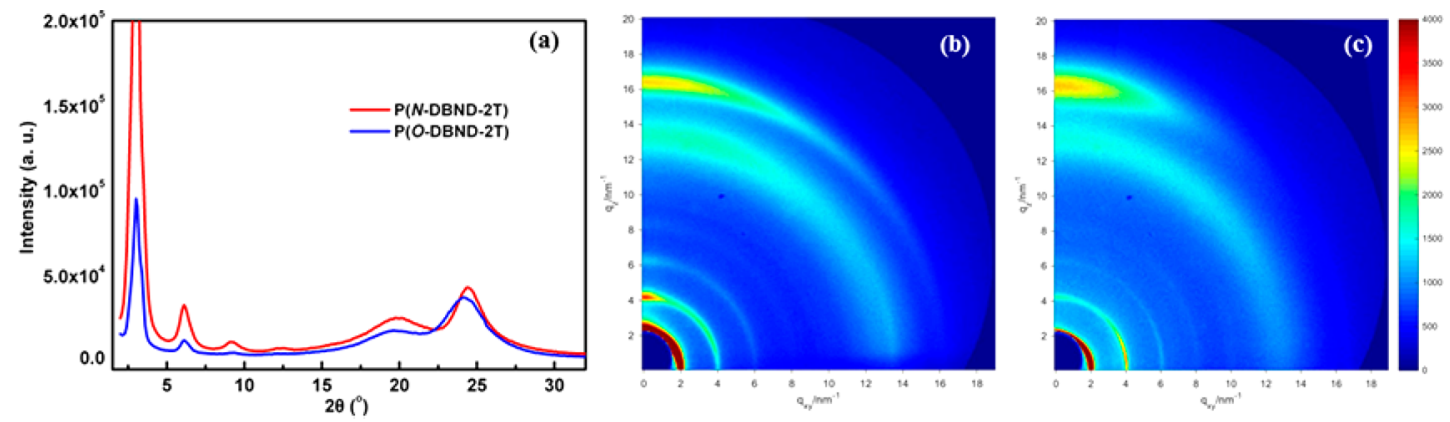

Figure 4. (a) GIXD out-of-plane linecults and 2D-GIXD patterns of (b) $\mathrm{P}(\mathrm{N}-\mathrm{DBND}-2 \mathrm{~T})$ and (c) $\mathrm{P}(\mathrm{O}-\mathrm{DBND}-2 \mathrm{~T})$ films after thermal annealing. 

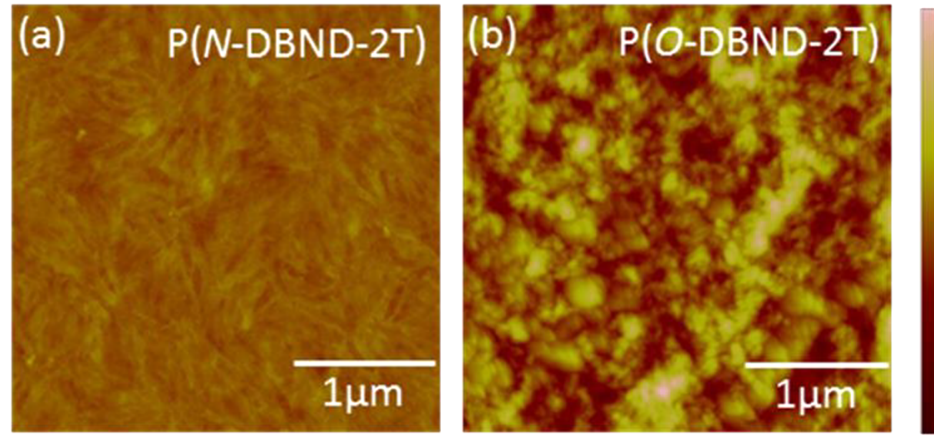

20nm
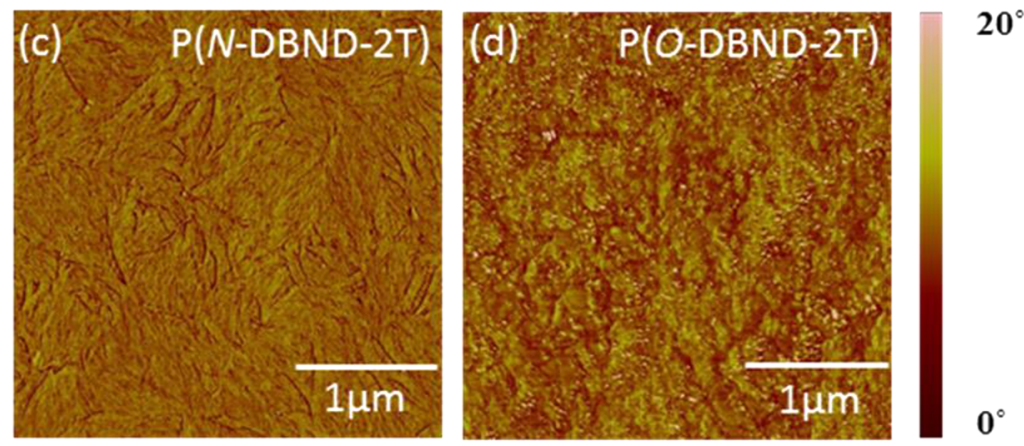

Figure 5. Tapping-mode AFM height images $(a$ and $b)$ and phase images $(c$ and $d)$ of $\mathrm{P}(N$-DBND-2T) and $\mathrm{P}(\mathrm{O}-\mathrm{DBND}-2 \mathrm{~T})$ films after thermal annealing.

a long-range ordered lamellar packing. Very interestingly, the diffraction peaks of both polymers appears at almost the same positions (as observed in the out-of-plane linecults and in-plane linecults, Figure S4), showing that their crystalline patterns are very similar, which indicates that $\mathrm{N}$-alkylation and $\mathrm{O}$-alkylation had little influence on the crystalline patterns. However, $\mathrm{P}(\mathrm{N}$ DBND-2T) exhibits stronger packing diffraction signals compared to $\mathrm{P}(\mathrm{O}-\mathrm{DBND}-2 \mathrm{~T})$, as illustrated in the out-ofplane linecults, which indicates $\mathrm{P}(N$-DBND-2T $)$ possesses higher degree of crystallinity in thin film state that $\mathrm{P}(\mathrm{O}-\mathrm{DBND}$ 2T). Higher degree of crystallinity of the $\mathrm{N}$-alkylated polymer is benefited from its stronger intermolecular interactions, which is in consistent of the temperature-dependent UV-vis absorption results and DFT calculations. In addition, the calculated $\pi-\pi$ stacking distance of $\mathrm{P}(\mathrm{N}-\mathrm{DBND}-2 \mathrm{~T})$ is $3.63 \AA$, remarkably smaller that of $\mathrm{P}(O-D B N D-2 T)$ (3.68 $\AA$ ). The smaller $\pi-\pi$ distance of $\mathrm{P}(\mathrm{N}$-DBND-2T $)$ promotes better frontier orbital overlap, which also contributes to the higher charge transport property. $^{35}$

2D-GIXD patterns of $\mathrm{P}(\mathrm{N}$-DBND-2T) (Figure $4 \mathrm{~b}$ ) and $\mathrm{P}(\mathrm{O}-\mathrm{DBND}-2 \mathrm{~T})$ (Figure $4 \mathrm{c}$ ) provided more information on the modes of orientation for both polymers. The lamellar stacking diffraction arcs extended from $q_{z}$ direction to $q_{x y}$ direction infer that both "face-on" and "edge-on" orientations exist in the thin films of both polymers; however, the $\pi-\pi$ stacking diffractions that could be observed at $q_{z}$ direction but not at $q_{x y}$ direction indicate that "face-on" arrangement is preferred for both polymers. ${ }^{36} \mathrm{P}(\mathrm{O}$-DBND-2T) seems to have even more fractions of "face-on" arrangement in the film state, since its $\pi-\pi$ stacking diffraction is more "localized" in the $q_{z}$ direction. $^{36,37}$

Although it is generally accepted that "edge-on" orientation of the polymeric backbone facilitates charge carrier transportation (such as most II based polymers), nevertheless, It should be point out $\mathrm{P}(\mathrm{N}-\mathrm{DBND}-2 \mathrm{~T})$ shows a mobility comparable as II based polymer with $2 \mathrm{~T}$ donors and similar side-chain (maximum $0.4 \mathrm{~cm}^{2} \mathrm{~V}^{-1} \mathrm{~s}^{-1}$ ) which prefers "edge-on" orientation, ${ }^{17}$ indicating that the planar structure of DBND, the stronger interactions between $N$-DBND-based polymers due to its higher polarity, and the presence of the "edge-on" phase (although in smaller amount compared to "face-on" phase might be the reasons for better charge transfer properties of $\mathrm{P}(\mathrm{N}$-DBND-2T). Since the molecule packing orientation could be finely tuned, ${ }^{38,39}$ we anticipate that better performance of $\mathrm{N}$ DBND based polymers could be obtained if all "edge-on" orientation could be realized.

Besides crystallinity, film morphology is another important factor that affects charge transport properties in organic semiconductor. And it is favorable for thin films to have interconnected domains in order to minimize crystallite grain boundaries. ${ }^{40}$ As illustrated in Figure 5, AFM image of the $\mathrm{P}(\mathrm{O}$ DBND-2T) film shows a rough and spherical morphology, while the $\mathrm{P}(\mathrm{N}$-DBND-2T) film shows fine, highly interconnected fibrillar domains with an obviously reduced surface roughness $(\mathrm{RMS}=0.47 \mathrm{~nm})$ compared to $\mathrm{P}(O-\mathrm{DBND}-2 \mathrm{~T})$ $(\mathrm{RMS}=2.31 \mathrm{~nm})$. Interconnected crystalline zones of the $\mathrm{P}(\mathrm{N}$ DBND-2T) film are formed presumably due to strong intermolecular $\pi-\pi$ interactions, which also accounts for its high charge carrier mobility.

\section{CONCLUSION}

With the development of an improved synthetic strategy, the $\mathrm{N}$-alkylation of DBND, a lactam-containing monomer used to be suitable for only O-alkylation, was now realized. The successful preparation of $N$-DBND gave us an opportunity, for the first time, to compare the influence of $\mathrm{N}$-alkylation and $\mathrm{O}$ alkylation on the OFET performance of polymer based on lactam-containing acceptor building blocks. It was found that $\mathrm{N}$-alkylation led to a polymer with higher polarity, which induced stronger interchain $\pi-\pi$ stacking, as evidenced by DFT calculation and temperature-dependent UV-vis spectroscopy. Although the crystalline patterns of the thin films were little 
affected when changing from $\mathrm{O}$-alkylation to $\mathrm{N}$-alkylation, $\pi-\pi$ stacking distance was shortened and the thin film became less rough and more well-interconnected fibers were formed, as evidenced by GIXD and AFM characterization. As the result, $\mathrm{P}(N$-DBND-2T $)$ showed much higher hole mobility $\left(0.55 \mathrm{~cm}^{2}\right.$ $\left.\mathrm{V}^{-1} \mathrm{~s}^{-1}\right)$, almost 100 times greater than that of $\mathrm{P}(O-\mathrm{DBND}$ 2T). These results indicate that the major difference between $\mathrm{N}$-alkylated and $\mathrm{O}$-alkylated conjugated polymers lies in their different polarity, although O-alkylated conjugated polymer has better solubility and larger molecular weight. It also infers that using a donor-acceptor repeating unit with stronger dipole moment will favor tighter interchain packing, which is a very important factor for the further improvement of OFET performance.

\section{ASSOCIATED CONTENT}

\section{S Supporting Information}

The Supporting Information is available free of charge on the ACS Publications website at DOI: 10.1021/acs.macromol.7b01575.

General procedures and experimental details, a table (Table S1) of alkylation conditions and results, figures of $I_{0-0} / I_{0-1}$ ratios (Figure $S 1$ ), electrochemical cyclic voltammetry (Figure S2), DFT calculations (Figure S3), GIXD (Figure S4), and NMR spectra (PDF)

\section{AUTHOR INFORMATION}

\section{Corresponding Authors}

*(X.Wang) E-mail: wangx@qibebt.ac.cn.

*(X.Wan) E-mail: wanxb@qibebt.ac.cn.

\section{ORCID $\odot$}

Xiaobo Wan: 0000-0001-5740-512X

\section{Author Contributions}

${ }^{\|}$These two authors (M.C. and Z.Z.) contributed equally to this work.

\section{Notes}

The authors declare no competing financial interest.

\section{ACKNOWLEDGMENTS}

This work is supported by the National Natural Science Foundation of China (NSFC51573204 and 21402220). The authors gratefully acknowledge the assistance of the scientists of the Diffuse X-ray Scattering Station in Beijing during the experiments.

\section{REFERENCES}

(1) Guo, X. G.; Facchetti, A.; Marks, T. J. Imide- and AmideFunctionalized Polymer Semiconductors. Chem. Rev. 2014, 114, 8943-9021.

(2) Liu, Z. T.; Zhang, G. X.; Cai, Z. X.; Chen, X.; Luo, H. W.; Li, Y. H.; Wang, J. G.; Zhang, D. Q. New Organic Semiconductors with Imide/Amide-Containing Molecular Systems. Adv. Mater. 2014, 26, 6965-6977.

(3) Kang, S. H.; Kumari, T.; Lee, S. M.; Jeong, M.; Yang, C. Densely Packed Random Quarterpolymers Containing Two Donor and Two Acceptor Units: Controlling Absorption Ability and Molecular Interaction to Enable Enhanced Polymer Photovoltaic Devices. Adv. Energy Mater. 2017, 7, 1700349.

(4) Fei, Z. P.; Chen, L.; Han, Y.; Gann, E.; Chesman, A. S. R.; McNeill, C. R.; Anthopoulos, T. D.; Heeney, M.; Pietrangelo, A. Alternating 5,5-Dimethylcyclopentadiene and Diketopyrrolopyrrole Copolymer Prepared at Room Temperature for High Performance
Organic Thin-Film Transistors. J. Am. Chem. Soc. 2017, 139, 80948097.

(5) Yang, J.; Wang, H.; Chen, J.; Huang, J.; Jiang, Y.; Zhang, J.; Shi, L.; Sun, Y.; Wei, Z.; Yu, G.; Guo, Y.; Wang, S.; Liu, Y. BisDiketopyrrolopyrrole Moiety as a Promising Building Block to Enable Balanced Ambipolar Polymers for Flexible Transistors. Adv. Mater. 2017, 29, 1606162.

(6) Deng, Y. F.; Liu, J.; Wang, J. T.; Liu, L. H.; Li, W. L.; Tian, H. K.; Zhang, X. J.; Xie, Z. Y.; Geng, Y. H.; Wang, F. S. Dithienocarbazole and Isoindigo based Amorphous Low Bandgap Conjugated Polymers for Efficient Polymer Solar Cells. Adv. Mater. 2014, 26, 471-476.

(7) Lei, T.; Cao, Y.; Fan, Y. L.; Liu, C. J.; Yuan, S. C.; Pei, J. HighPerformance Air-Stable Organic Field-Effect Transistors: IsoindigoBased Conjugated Polymers. J. Am. Chem. Soc. 2011, 133, 6099-6101.

(8) Cao, J.; Liao, Q.; Du, X.; Chen, J.; Xiao, Z.; Zuo, Q.; Ding, L. A pentacyclic aromatic lactam building block for efficient polymer solar cells. Energy Environ. Sci. 2013, 6, 3224.

(9) Cui, W. B.; Wudl, F. Dithienylbenzodipyrrolidone: New Acceptor for Donor-Acceptor Low Band Gap Polymers. Macromolecules 2013, 46, 7232-7238.

(10) Kroon, R.; Diaz de Zerio Mendaza, A.; Himmelberger, S.; Bergqvist, J.; Backe, O.; Faria, G. C.; Gao, F.; Obaid, A.; Zhuang, W. L.; Gedefaw, D.; Olsson, E.; Inganas, O.; Salleo, A.; Muller, C.; Andersson, M. R. A New Tetracyclic Lactam Building Block for Thick, Broad-Bandgap Photovoltaics. J. Am. Chem. Soc. 2014, 136, 1157811581.

(11) Poduval, M. K.; Burrezo, P. M.; Casado, J.; López Navarrete, J. T.; Ortiz, R. P.; Kim, T.-H. Novel Thiophene-Phenylene-Thiophene Fused Bislactam-Based Donor-Acceptor Type Conjugate Polymers: Synthesis by Direct Arylation and Properties. Macromolecules 2013, 46, 9220-9230.

(12) Lei, T.; Dou, J. H.; Cao, X. Y.; Wang, J. Y.; Pei, J. A BDOPVBased Donor-Acceptor Polymer for High-Performance n-Type and Oxygen-Doped Ambipolar Field-Effect Transistors. Adv. Mater. 2013, $25,6589-6593$

(13) Meager, I.; Nikolka, M.; Schroeder, B. C.; Nielsen, C. B.; Planells, M.; Bronstein, H.; Rumer, J. W.; James, D. I.; Ashraf, R. S.; Sadhanala, A.; Hayoz, P.; Flores, J. C.; Sirringhaus, H.; McCulloch, I. Thieno[3,2-b] thiophene Flanked Isoindigo Polymers for High Performance Ambipolar OFET Applications. Adv. Funct. Mater. 2014, 24, 7109-7115.

(14) Yue, W.; Ashraf, R. S.; Nielsen, C. B.; Collado-Fregoso, E.; Niazi, M. R.; Yousaf, S. A.; Kirkus, M.; Chen, H. Y.; Amassian, A.; Durrant, J. R.; McCulloch, I. A Thieno[3,2-b][1] benzothiophene Isoindigo Building Block for Additive- and Annealing-Free HighPerformance Polymer Solar Cells. Adv. Mater. 2015, 27, 4702-4707.

(15) Zhao, N.; Ai, N.; Cai, M.; Wang, X.; Pei, J.; Wan, X. B. Thiophene-fused isoindigo based conjugated polymers for ambipolar organic field-effect transistors. Polym. Chem. 2016, 7, 235-243.

(16) Chen, X. X.; Zhang, Z. J.; Ding, Z. C.; Liu, J.; Wang, L. X. Diketopyrrolopyrrole-based Conjugated Polymers Bearing Branched Oligo(Ethylene Glycol) Side Chains for Photovoltaic Devices. Angew. Chem., Int. Ed. 2016, 55, 10376-10380.

(17) Lei, T.; Dou, J. H.; Pei, J. Influence of Alkyl Chain Branching Positions on the Hole Mobilities of Polymer Thin-Film Transistors. Adv. Mater. 2012, 24, 6457-6461.

(18) Yang, S. F.; Liu, Z. T.; Cai, Z. X.; Luo, H. W.; Qi, P. L.; Zhang, G. X.; Zhang, D. Q. Conjugated Donor-Acceptor Polymers Entailing Pechmann Dye-Derived Acceptor with Siloxane-Terminated Side Chains Exhibiting Balanced Ambipolar Semiconducting Behavior. Macromolecules 2016, 49, 5857-5865.

(19) Huang, J. Y.; Mao, Z. P.; Chen, Z. H.; Gao, D.; Wei, C. Y.; Zhang, W. F.; Yu, G. Diazaisoindigo-Based Polymers with HighPerformance Charge-Transport Properties: From Computational Screening to Experimental Characterization. Chem. Mater. 2016, 28, 2209-2218.

(20) Kim, G.; Kang, S. J.; Dutta, G. K.; Han, Y. K.; Shin, T. J.; Noh, Y. Y.; Yang, C. A Thienoisoindigo-Naphthalene Polymer with Ultrahigh Mobility of $14.4 \mathrm{~cm} 2 / \mathrm{V} \cdot \mathrm{s}$ That Substantially Exceeds 
Benchmark Values for Amorphous Silicon Semiconductors. J. Am. Chem. Soc. 2014, 136, 9477-9483.

(21) Lei, T.; Dou, J. H.; Ma, Z. J.; Liu, C. J.; Wang, J. Y.; Pei, J. Chlorination as a useful method to modulate conjugated polymers: balanced and ambient-stable ambipolar high-performance field-effect transistors and inverters based on chlorinated isoindigo polymers. Chem. Sci. 2013, 4, 2447-2452.

(22) Lei, T.; Dou, J. H.; Ma, Z. J.; Yao, C. H.; Liu, C. J.; Wang, J. Y.; Pei, J. Ambipolar Polymer Field-Effect Transistors Based on Fluorinated Isoindigo: High Performance and Improved Ambient Stability. J. Am. Chem. Soc. 2012, 134, 20025-20028.

(23) He, B.; Pun, A. B.; Klivansky, L. M.; McGough, A. M.; Ye, Y. F.; Zhu, J. F.; Guo, J. H.; Teat, S. J.; Liu, Y. Thiophene Fused Azacoronenes: Regioselective Synthesis, Self-Organization, Charge Transport and Its Incorporation in Conjugated Polymers. Chem. Mater. 2014, 26, 3920-3927.

(24) Breugst, M.; Mayr, H. Ambident Reactivities of Pyridone Anions. J. Am. Chem. Soc. 2010, 132, 15380-15389.

(25) Guérette, M.; Najari, A.; Maltais, J.; Pouliot, J. R.; Dufresne, S.; Simoneau, M.; Besner, S.; Charest, P.; Leclerc, M. New Processable Phenanthridinone-Based Polymers for Organic Solar Cell Applications. Adv. Energy Mater. 2016, 6, 1502094.

(26) Liu, M.; Liang, Y. M.; Chen, P. H.; Chen, D. C.; Liu, K. K.; Li, Y. C.; Liu, S. J.; Gong, X.; Huang, F.; Su, S. J.; Cao, Y. Three pyrido $[2,3,4,5-\mathrm{lmn}]$ phenanthridine derivatives and their large band gap copolymers for organic solar cells. J. Mater. Chem. A 2014, 2, 321325.

(27) Zhu, D. Q.; Zhu, Q. Q.; Gu, C. T.; Ouyang, D.; Qiu, M.; Bao, X. C.; Yang, R. Q. Alkoxyl Side Chain Substituted Thieno[3,4-c]pyrrole4,6-dione To Enhance Photovoltaic Performance with Low Steric Hindrance and High Dipole Moment. Macromolecules 2016, 49, 5788-5795.

(28) Cai, M.; Bao, X. C.; Wang, X.; Zhang, H. R.; Qiu, M.; Yang, R. Q.; Yang, C. M.; Wan, X. B. From Isoindigo to Dibenzonaphthyridinedione: A Building Block for Wide-Bandgap Conjugated Polymers with High Power Conversion Efficiency. Chem. Mater. 2016, 28, 6196-6206.

(29) Voronina, Y. K.; Krivolapov, D. B.; Bogdanov, A. V.; Mironov, V. F.; Litvinov, I. A. An unusual conformation of 1,1'-dimethylisoindigo in crystals. J. Struct. Chem. 2012, 53, 413-416.

(30) Blass, B. E.; Burt, T. M.; Liu, S.; Portlock, D. E.; Swing, E. M. A facile $\mathrm{KF} / \mathrm{Al} 2 \mathrm{O} 3$ mediated, selective alkylation of benzodiazepin-2,5diones. Tetrahedron Lett. 2000, 41, 2063-2066.

(31) Zhu, D.; Bao, X.; Zhu, Q.; Gu, C.; Qiu, M.; Wen, S.; Wang, J.; Shahid, B.; Yang, R. Thienothiophene-based copolymers for highperformance solar cells, employing different orientations of the thiazole group as a $\pi$ bridge. Energy Environ. Sci. 2017, 10, 614-620.

(32) Bredas, J. L. Mind the gap! Mater. Horiz. 2014, 1, 17-19.

(33) Lei, T.; Cao, Y.; Zhou, X.; Peng, Y.; Bian, J.; Pei, J. Systematic Investigation of Isoindigo-Based Polymeric Field-Effect Transistors: Design Strategy and Impact of Polymer Symmetry and Backbone Curvature. Chem. Mater. 2012, 24, 1762-1770.

(34) Yao, H. F.; Ye, L.; Hou, J. X.; Jang, B.; Han, G. C.; Cui, Y.; Su, G. M.; Wang, C.; Gao, B. W.; Yu, R. N.; Zhang, H.; Yi, Y. P.; Woo, H. Y.; Ade, H.; Hou, J. H. Achieving Highly Efficient Nonfullerene Organic Solar Cells with Improved Intermolecular Interaction and Open-Circuit Voltage. Adv. Mater. 2017, 29, 1700254.

(35) Coropceanu, V.; Cornil, J.; da Silva Filho, D. A.; Olivier, Y.; Silbey, R; Brédas, J. L. Charge Transport in Organic Semiconductors. Chem. Rev. 2007, 107, 926-952.

(36) Mueller, C. J.; Gann, E.; Singh, C. R.; Thelakkat, M.; McNeill, C. R. Control of Molecular Orientation in Polydiketopyrrolopyrrole Copolymers via Diffusive Noncovalent Interactions. Chem. Mater. 2016, 28, 7088-7097.

(37) Schott, S.; Gann, E.; Thomsen, L.; Jung, S. H.; Lee, J. K.; McNeill, C. R.; Sirringhaus, H. Charge-Transport Anisotropy in a Uniaxially Aligned Diketopyrrolopyrrole-Based Copolymer. Adv. Mater. 2015, 27, 7356-7364.
(38) Kim, Y.; Long, D. X.; Lee, J.; Kim, G.; Shin, T. J.; Nam, K. W.; Noh, Y. Y.; Yang, C. A Balanced Face-On to Edge-On Texture Ratio in Naphthalene Diimide-Based Polymers with Hybrid Siloxane Chains Directs Highly Efficient Electron Transport. Macromolecules 2015, 48, 5179-5187.

(39) Mei, J. G.; Wu, H. C.; Diao, Y.; Appleton, A.; Wang, H.; Zhou, Y.; Lee, W. Y.; Kurosawa, T.; Chen, W. C.; Bao, Z. N. Effect of Spacer Length of Siloxane-Terminated Side Chains on Charge Transport in Isoindigo-Based Polymer Semiconductor Thin Films. Adv. Funct. Mater. 2015, 25, 3455-3462.

(40) Tsao, H. N.; Mullen, K. Improving polymer transistor performance via morphology control. Chem. Soc. Rev. 2010, 39, $2372-2386$. 